\title{
Validation of a Proposed Algorithm for Assistance Titration During Proportional Assist Ventilation With Load-Adjustable Gain Factors
}

\author{
Vasilios Amargiannitakis, Ioannis Gialamas, Emmanouil Pediaditis, Stella Soundoulounaki, \\ Georgios Prinianakis, Katerina Vaporidi, Evangelia Akoumianaki, Athanasia Proklou, \\ Christina Alexopoulou, Dimitrios Georgopoulos, and Eumorfia Kondili
}

\begin{abstract}
BACKGROUND: The present study aimed to validate a recently proposed algorithm for assistance titration during proportional assist ventilation with load-adjustable gain factors, based on a noninvasive estimation of maximum inspiratory pressure (peak $\mathbf{P}_{\text {mus }}$ ) and inspiratory effort (pressure-time product $[P T P]$ peak $\left.\mathbf{P}_{\text {mus }}\right)$. METHODS: Retrospective analysis of the recordings obtained from 26 subjects ventilated on proportional assist ventilation with load-adjustable gain factors under different conditions, each considered as an experimental case. The estimated inspiratory output (peak $\mathbf{P}_{\text {mus }}$ ) and effort (PTP-peak $\mathbf{P}_{\text {mus }}$ ) were compared with the actual-determined by the measurement of transdiaphragmatic pressure- and the derived PTP. Validation of the algorithm was performed by assessing the accuracy of peak $\mathbf{P}_{\text {mus }}$ in predicting the actual inspiratory muscle effort and indicating the appropriate level of assist. RESULTS: In the 63 experimental cases analyzed, a limited agreement was observed between the estimated and the actual inspiratory muscle pressure $\left(-11\right.$ to $\left.10 \mathrm{~cm} \mathrm{H}_{2} \mathrm{O}\right)$ and effort $(-82$ to $125 \mathrm{~cm} \mathrm{H} \mathrm{H}_{2} \mathrm{O} \times \mathrm{s} / \mathrm{min}$ ). The sensitivity and specificity of peak $P_{\text {mus }}$ to predict the range of the actual inspiratory effort was $81.2 \%$ and $58.1 \%$, respectively. In $49 \%$ of experimental cases, the level of assist indicated by the algorithm differed from that indicated by the transdiaphragmatic pressure and PTP. CONCLUSIONS: The proposed algorithm had limited accuracy in estimating inspiratory muscle effort and with indicating the appropriate level of assist. Key words: assistance; titration; proportional assist ventilation; inspiratory muscles output. [Respir Care 2020;65(1):36-44. (c) 2020 Daedalus Enterprises]
\end{abstract}

\section{Introduction}

Proportional assist ventilation (PAV) with load-adjustable gain factors $(\mathrm{PAV}+$ ) is a patient effort-driven mode of assisted ventilation, in which the ventilator provides

\footnotetext{
Drs Amargiannitakis, Gialamas, Pediaditis, Soundoulounaki, Prinianakis, Vaporidi, Akoumianaki, Proklou, Alexopoulou, Georgopoulos, and Kondili are affiliated with the Department of Intensive Care Medicine, University Hospital of Heraklion and School of Medicine, University of Crete, Heraklion, Crete, Greece.
}

Drs Amargiannitakis and Gialamas contributed equally to this work.

Drs Kondili, Vaporidi, and Georgopoulos have received lecture fees (honoraria) from Covidien.

Covidien was not involved in any aspect of the design or conduct of the study, the data analysis, or the manuscript preparation and presentation.

Supplementary material related to this paper is available at http:// www.rcjournal.com. pressure proportional to the patient's instant flow and volume, and thus is proportional to the elastic and resistive work load. ${ }^{1-3}$ Previous studies demonstrated the effectiveness of PAV + relative to conventional assisted modes of mechanical ventilation. ${ }^{4-8}$ However, clinical use of this mode is limited, likely due to the lack of established criteria for titrating the level of support. The conventional method of assistance titration, based on tidal volume $\left(\mathrm{V}_{\mathrm{T}}\right)$ and breathing frequency may be hindered during ventilation on $\mathrm{PAV}+$; with this mode, significant variability in $\mathrm{V}_{\mathrm{T}}$ has been observed, and patients retain their desired breathing pattern..$^{4,9}$

\footnotetext{
Correspondence: Eumorfia Kondili MD PhD, Department of Intensive Care Medicine, University Hospital of Heraklion, Voutes 71110, Heraklion, Crete, Greece. E-mail: kondylie@uoc.gr.
}

DOI: $10.4187 /$ respcare. 06988 
A clinical algorithm has been introduced to titrate the level of assistance during ventilation on $\mathrm{PAV}+$, which uses a noninvasive estimation of respiratory muscle output (maximum inspiratory pressure [peak $\mathrm{P}_{\text {mus }}$ ]) and effort (pressure-time product [PTP] of peak $\mathrm{P}_{\text {mus }}{ }^{10}$ The level of support used peak $\mathrm{P}_{\text {mus }}$ to target a predefined range (5$10 \mathrm{~cm} \mathrm{H}_{2} \mathrm{O}$ ), which is estimated to correspond to the generally accepted range of inspiratory muscle effort (PTP of $\left.50-150 \mathrm{~cm} \mathrm{H}_{2} \mathrm{O} \times \mathrm{s} / \mathrm{min}\right)$.

Clinical applicability of this algorithm was evaluated in a group of subjects on mechanical ventilation with various forms of acute respiratory failure. ${ }^{10}$ By adjusting the gain in PAV + by using this algorithm, the majority of the subjects were successfully weaned from the ventilator. The investigators concluded that peak $\mathrm{P}_{\text {mus }}$ and the derived pressure time product of peak $\mathrm{P}_{\text {mus }}$ might serve as accurate surrogates of pressure generated by the respiratory muscles and inspiratory muscle effort, respectively. ${ }^{10}$ However, the calculation of peak $\mathrm{P}_{\text {mus }}$ and PTP-peak $\mathrm{P}_{\text {mus }}$ was based on assumptions that might result in significant discrepancies between estimated and actual inspiratory muscle output and effort, as measured by transdiaphragmatic pressure $\left(\mathrm{P}_{\mathrm{di}}\right)$ and the derived PTP- $\mathrm{P}_{\mathrm{di}}$.

$\mathrm{Su}$ et $\mathrm{al}^{11}$ previously investigated the accuracy of this method in subjects who were critically ill. Peak $\mathrm{P}_{\text {mus }}$ and PTP-peak $\mathrm{P}_{\text {mus }}$ were compared with peak muscle pressure and effort calculated from esophageal pressure $\left(\mathrm{P}_{\mathrm{es}}\right)$ at different levels of ventilator assist. Weak correlations were observed between both peak $\mathrm{P}_{\text {mus }}$ and peak muscle $\mathrm{P}_{\mathrm{es}}$, and the derived PTPs. However, this study was limited by the small number of subjects, the lack of gastric pressure measurement, and the lack of $\mathrm{P}_{\mathrm{di}}$ measurement. Furthermore, the investigators did not evaluate the accuracy of peak $\mathrm{P}_{\text {mus }}$ for predicting inspiratory effort and indicating the appropriate level of assist. The present study aimed to evaluate the association between estimated and the actual values of inspiratory muscle output and effort by comparing peak $\mathrm{P}_{\text {mus }}$ with $\mathrm{P}_{\mathrm{di}}$, and PTP-peak $\mathrm{P}_{\text {mus }}$ with PTP- $\mathrm{P}_{\mathrm{di}}$; identify confounding physiologic factors that contribute to discrepancies between compared variables; and validate the accuracy of the proposed algorithm for assistance titration.

\section{Methods}

We retrospectively analyzed the recordings of 26 subjects who participated in 3 previous research protocols. The ethics committee of the hospital approved the study design, and informed consent was obtained from the subjects or their families. This study was performed at the Department of Intensive Care Medicine, University Hospital of Heraklion, Heraklion, Crete, Greece. All the subjects were ventilated on PAV+ (Puritan-Bennett 840 ventilator, Medtronic, PLC, Ireland) at different levels of assist, and instrumented with esophageal and gastric balloons. As

\section{QUICK LOOK}

\section{Current knowledge}

During proportional assist ventilation with load-adjustable gain factors $(\mathrm{PAV}+)$, the conventional method of assistance titration, based on tidal volume and breathing frequency, may be hindered because significant variability in tidal volume has been observed in this mode and patients retain their desired breathing largely independent of mechanical load and assistance level.

\section{What this paper contributes to our knowledge}

The present study retrospectively evaluated an algorithm for assistance titration during ventilation on $\mathrm{PAV}+$. The algorithm showed limited accuracy for indicating the appropriate assist level.

part of the individual research protocols, 15 subjects were studied with and without an artificial increase in the elastic work of breathing, accomplished by applying sandbags to the entire surface of the chest and abdominal wall. Each subject at each experimental condition was regarded as an individual experimental case.

\section{Measurements}

Flow, volume, airway pressure $\left(\mathrm{P}_{\mathrm{aw}}\right), \mathrm{P}_{\mathrm{e}}$, gastric pressure, and $\mathrm{P}_{\mathrm{di}}\left(\mathrm{P}_{\mathrm{di}}=\right.$ gastric pressure $\left.-\mathrm{P}_{\mathrm{es}}\right)$ pressures were measured on a breath-by-breath basis, as previously described. ${ }^{4,12}$ The proper position of the esophageal and gastric balloons was initially verified by using standard tests and procedures. ${ }^{13}$

\section{Data Analysis}

In each experimental case, at least 10 breaths over a period of 3 min were randomly analyzed and averaged to obtain breath variables for the corresponding experimental case. Breaths with a low-quality $\mathrm{P}_{\mathrm{di}}$ signal were excluded. $\mathrm{P}_{\mathrm{di}}$ was defined as the highest value of $\mathrm{P}_{\mathrm{di}}$ during inspiration, and the inspiratory effort per breath $\left(\right.$ PTP- $\left.\mathrm{P}_{\mathrm{di}}\right)$ and PTP- $\mathrm{P}_{\mathrm{di}} /$ min were quantified. ${ }^{4,12}$ As previously described, the following were measured in each selected breath: the neural and mechanical inspiratory times; the difference between neural and mechanical inspiratory times $(\Delta t)$; the rate of the rise of $\mathrm{P}_{\mathrm{di}}(\mathrm{dp} / \mathrm{dt})$; the triggering delay; the intrinsic PEEP (PEEPi); and the presence of expiratory muscle activity and contribution of the diaphragm and inspiratory rib cage muscles to inspiratory output (see the supplementary materials at http://www.rcjournal. com). 4,12,14 The estimated peak $\mathrm{P}_{\text {mus }}$ and the estimated 
inspiratory effort (PTP-peak $\mathrm{P}_{\text {mus }}$ ) were calculated by using the formulas proposed by Carteaux et $\mathrm{a}^{10}$ as follow:

$$
\text { peak } \mathrm{P}_{\text {mus }}=\left(\mathrm{P}_{\mathrm{aw}} \text { Peak }-\mathrm{PEEP}\right) \times \frac{100 \text {-gain }}{\text { gain }} \text {. }
$$

Where $\mathrm{P}_{\mathrm{aw}}$ Peak $=$ peak inspiratory $\mathrm{P}_{\mathrm{aw}}$ and gain $=$ the level of assist.

$$
\text { PTP }- \text { peak } \mathrm{P}_{\text {mus }}=\frac{\text { peak } \mathrm{P}_{\text {mus }} \times \mathrm{T}_{\mathrm{I}} \mathrm{m}}{2} \times \mathrm{f}
$$

where $\mathrm{T}_{\mathrm{I}} \mathrm{m}=$ mechanical inspiratory time and $\mathrm{f}=$ breathing frequency (see the supplementary materials at http:// www.rcjournal.com). ${ }^{10}$

The differences were calculated between peak $\mathrm{P}_{\text {mus }}$ and $\mathrm{P}_{\mathrm{di}}(\mathrm{dP})$, and between PTP-peak $\mathrm{P}_{\text {mus }} / \mathrm{min}$ and PTP- $\mathrm{P}_{\mathrm{di}} / \mathrm{min}(\Delta \mathrm{PTP}) ; \mathrm{dP}$ and $\Delta \mathrm{PTP} / \mathrm{min}$ were also expressed as the percentage of $\mathrm{P}_{\mathrm{di}}\left(\mathrm{dP} \% \mathrm{P}_{\mathrm{di}}\right)$ and PTP- $\mathrm{P}_{\mathrm{di}} / \mathrm{min}$ $\left(\Delta \mathrm{PTP} / \mathrm{min} \%\right.$ PTP- $\left.\mathrm{P}_{\mathrm{di}} / \mathrm{min}\right)$, respectively.

Correlations between peak $\mathrm{P}_{\text {mus }}$, PTP-peak $\mathrm{P}_{\text {mus }}, \mathrm{dP}$, and $\triangle \mathrm{PTP}$ with each of the following possible confounding physiologic factors were evaluated (as independent variables): dp/dt (an index of respiratory drive); PEEPi; presence of expiratory muscle activity (yes/no); ratio of gastric pressure to $\mathrm{P}_{\mathrm{es}}$ changes during inspiration, an index of contribution of the diaphragm and inspiratory rib cage muscles to the inspiratory output); triggering delay; and difference between the mechanical inspiratory time and the neural inspiratory time $(\Delta \mathrm{t})$.

\section{Validation of the Proposed Algorithm}

The validation of the proposed algorithm was performed by assessing the accuracy of peak $\mathrm{P}_{\text {mus }}$ to correctly classify the actual inspiratory muscle effort, determined by the PTP- $\mathrm{P}_{\mathrm{di}}$. Specifically, in each experimental case, we assessed whether the measured PTP- $\mathrm{P}_{\mathrm{di}}$ was within the range of that predicted by the peak $\mathrm{P}_{\text {mus }}$ inspiratory muscle effort (ie, $<50 \mathrm{~cm} \mathrm{H}_{2} \mathrm{O} \times \mathrm{s} / \mathrm{min}$ to peak $\mathrm{P}_{\text {mus }}$ of $<5 \mathrm{~m} \mathrm{H}_{2} \mathrm{O}$ $50-150 \mathrm{~cm} \mathrm{H}_{2} \mathrm{O} \times$ s/min to peak $\mathrm{P}_{\text {mus }}$ of $5-10 \mathrm{~cm} \mathrm{H}_{2} \mathrm{O}$ and $>150 \mathrm{~cm} \mathrm{H}_{2} \mathrm{O} \times \mathrm{s} / \mathrm{min}$, to peak $\mathrm{P}_{\text {mus }}$ of $>10 \mathrm{~cm} \mathrm{H}_{2} \mathrm{O}$, respectively). Analysis was performed in all experimental cases combined and in 3 subgroups, determined by the peak $\mathrm{P}_{\text {mus }}$ value: $<5,5-10$, and $>10 \mathrm{~cm} \mathrm{H}_{2} \mathrm{O}$ (see the supplementary materials at http://www.rcjournal.com).

\section{Statistical Analysis}

Continuous variables are reported as the mean \pm SD for normally distributed data, and median and interquartile range (IQR) for non-normally distributed data. Continuous variables were compared (2-tailed) by using the Wilcoxon test (paired sample). Linear regression analysis was used, and the coefficient of determination was calculated to examine the relationship between continuous variables. Analysis of residuals confirmed the assumptions of linearity.
The agreement (bias) between variables was expressed as the mean of the corresponding differences. The limits of agreements were expressed as the mean $\pm 1.96 \mathrm{SD}$, and $95 \%$ CIs of the bias were calculated by using the Bland-Altman method. The correlation between continuous variables was assessed by using Spearman's rho, followed (when indicated) by multiple regression analysis. Validation of the algorithm was performed by using receiver operating characteristic curve analysis. All statistical tests were 2-tailed, and $P<.05$ was considered to be statistically significant. Statistical analysis was performed by using MedCalc Statistical Software version 15.8 (MedCalc Software bvba, Ostend, Belgium). Statistical analysis was reviewed by an external statistician to confirm that no conflict existed between identified correlations and investigators' interpretations. The sample size required obtaining a size effect of 0.8 between compared variables for a 2 -sided $\alpha$ of 0.05 , and study power of $80 \%$ was calculated to be 25 cases.

\section{Results}

The recordings of 26 subjects with respiratory failure from different causes were included in the analysis. Subject demographic and clinical characteristics are presented in Supplementary Table 1 (see the supplementary materials at http://www.rcjournal.com). In 10 subjects, as part of the original study design, we retrieved recordings at different levels of ventilator assist (up to 4). Fifteen subjects were studied before and after the experimental increase in elastic respiratory work load, at either the same (10 subjects) or different (5 subjects) levels of assistance. Sixtythree different levels of assistance were identified, and a total of 725 sufficient breaths were available for analysis. The mean \pm SD level of assistance was $50 \pm 14.5 \%$. Physiologic variables and breath characteristics (median values and IQR) are shown in Table 1.

The median (IQR) difference between PTP-peak $\mathrm{P}_{\mathrm{mus}} / \mathrm{min}$ and PTP- $\mathrm{P}_{\mathrm{di}} / \mathrm{min}$ was $14.65(-13.52$ to 45.615$)$ $\mathrm{cm} \mathrm{H}_{2} \mathrm{O} \times \mathrm{s} / \mathrm{min}$; the median (IQR) difference between peak $\mathrm{P}_{\text {mus }}$ and $\mathrm{P}_{\mathrm{di}}$ was 0.68 ( -3.29 to 2.11$) \mathrm{cm} \mathrm{H}_{2} \mathrm{O}$. The PTP-peak $\mathrm{P}_{\text {mus }} / \min$ (median, $87.15 \mathrm{~cm} \mathrm{H}_{2} \mathrm{O} \times \mathrm{s} / \mathrm{min}$ ) was significantly higher than PTP- $\mathrm{P}_{\mathrm{di}} /$ per min (median, $\left.71.19 \mathrm{~cm} \mathrm{H}_{2} \mathrm{O} \times \mathrm{s} / \mathrm{min} ; P=.04\right)$. However, in 38 experimental cases $(60.31 \%)$, the difference between the 2 variables was negative (PTP-peak $\mathrm{P}_{\text {mus }}$ was lower than PTP- $\left.\mathrm{P}_{\mathrm{di}} / \mathrm{min}\right)$. No significant difference was found between peak $\mathrm{P}_{\text {mus }}$ (median, 8.77) $\mathrm{cm} \mathrm{H}_{2} \mathrm{O}$ and $\mathrm{P}_{\mathrm{di}}$ (median, 8.50; $P=.45$ ) (Fig. 1).

A significant linear relationship was present between peak $\mathrm{P}_{\text {mus }}$ and $\mathrm{P}_{\mathrm{di}}$ (coefficient of determination, $\mathrm{R}^{2}=0.346$, slope $=0.5253, P<.001)$, and between PTP-peak $\mathrm{P}_{\text {mus }}$ and PTP-P $\mathrm{P}_{\mathrm{di}}\left(\mathrm{R}^{2}=0.33\right.$, slope $\left.=0.729, P<.001\right)$; however, there was significant scatter in the measurements. Scatter plots and corresponding regression equations are 
Table 1. Inspiratory Effort Indices and Breath Characteristics

\begin{tabular}{|c|c|c|}
\hline Characteristic & Median & IQR \\
\hline \multicolumn{3}{|l|}{ Inspiratory effort indices } \\
\hline peak $\mathrm{P}_{\text {mus }}, \mathrm{cm} \mathrm{H}_{2} \mathrm{O}$ & 8.770 & $5.9-11.99$ \\
\hline PTP-peak $\mathrm{P}_{\text {mus }}, \mathrm{cm} \mathrm{H}_{2} \mathrm{O} \times \mathrm{s} / \mathrm{min}$ & 87.150 & 59-127.4 \\
\hline $\mathrm{P}_{\mathrm{di}}, \mathrm{cm} \mathrm{H}_{2} \mathrm{O}$ & 8.5 & $5.42-11.68$ \\
\hline PTP- $\mathrm{P}_{\mathrm{di}}, \mathrm{cm} \mathrm{H}_{2} \mathrm{O} \times \mathrm{s} / \mathrm{min}$ & 71.190 & $42.9-113.6$ \\
\hline $\mathrm{dP}, \mathrm{cm} \mathrm{H}_{2} \mathrm{O}$ & -0.68 & -3.29 to 2.11 \\
\hline $\mathrm{dP} \% \mathrm{Pdi}$ & 10.11 & -31.4 to 33.1 \\
\hline$\Delta \mathrm{PTP}, \mathrm{cm} \mathrm{H}_{2} \mathrm{O}$ & 14.65 & -13.5 to 45.6 \\
\hline$\Delta$ РTP $\%$ PTP-P ${ }_{\mathrm{di}}, \%$ & 20.8 & -20.6 to 90.8 \\
\hline \multicolumn{3}{|l|}{ Breath characteristics } \\
\hline $\mathrm{V}_{\mathrm{T}}, \mathrm{L}$ & 0.39 & $0.33-0.50$ \\
\hline $\mathrm{T}_{\mathrm{I}}$ neural, s & 0.65 & $0.49-0.91$ \\
\hline $\mathrm{T}_{\mathrm{I}} \mathrm{mec}, \mathrm{s}$ & 0.97 & $0.81-1.17$ \\
\hline $\mathrm{T}_{E}, \mathrm{~s}$ & 1.89 & $1.55-2.55$ \\
\hline$\Delta \mathrm{t}, \mathrm{s}$ & 0.33 & $0.22-0.46$ \\
\hline $\mathrm{T}_{\text {tot }}$ & 2.79 & $2.16-3.21$ \\
\hline Delay trigger, $\mathrm{s}$ & 0.17 & $0.13-0.2$ \\
\hline $\mathrm{dp} / \mathrm{dt}, \mathrm{cm} \mathrm{H}_{2} \mathrm{O} / \mathrm{s}$ & 13.8 & $8.4-23.5$ \\
\hline $\mathrm{f}$, breaths/min & 21.6 & $18.8-27.8$ \\
\hline $\mathrm{PEEPi}, \mathrm{cm} \mathrm{H}_{2} \mathrm{O}$ & 1.17 & $0.47-1.8$ \\
\hline PEEP external, $\mathrm{cm} \mathrm{H}_{2} \mathrm{O}$ & 9.4 & $6-7.8$ \\
\hline$\Delta \mathrm{P}_{\mathrm{gas}} / \Delta \mathrm{P}_{\mathrm{eos}}$ & 0.19 & $0.11-0.33$ \\
\hline \multicolumn{3}{|c|}{$\overline{\mathrm{IQR}=25 \text { th-75th interquartile range }}$} \\
\hline \multirow{2}{*}{\multicolumn{3}{|c|}{$\begin{array}{l}\text { peak } \mathrm{P}_{\text {mus }}=\text { calculated (from the formula) peak inspiratory pressure } \\
\text { PTP = pressure-time product }\end{array}$}} \\
\hline $\begin{array}{l}\mathrm{PTP}=\text { pressure-time product } \\
\mathrm{P}_{\mathrm{di}}=\text { transdiaphragmatic pressure }\end{array}$ & & \\
\hline \multicolumn{3}{|l|}{$\begin{array}{l}\mathrm{P}_{\mathrm{di}}=\text { transdiaphragmatic pressure } \\
\mathrm{dP}=\text { difference between peak } \mathrm{P}_{\text {mus }} \text { and } \mathrm{Pdi}\end{array}$} \\
\hline \multicolumn{3}{|l|}{$\mathrm{V}_{\mathrm{T}}=$ tidal volume } \\
\hline \multicolumn{3}{|l|}{$\mathrm{T}_{1}$ neural $=$ neural inspiratory time } \\
\hline \multicolumn{3}{|l|}{$\mathrm{T}_{\mathrm{I}} \mathrm{mec}=$ mechanical inspiratory time } \\
\hline \multicolumn{3}{|c|}{$\mathrm{T}_{E}=$ expiratory time } \\
\hline \multirow{2}{*}{\multicolumn{3}{|c|}{$\begin{array}{l}\Delta \mathrm{t}=\text { difference between mechanical and neural inspiratory } \\
\mathrm{T}_{\text {tot }}=\text { the total breath duration }\end{array}$}} \\
\hline \multirow{2}{*}{\multicolumn{3}{|c|}{$\begin{array}{l}T_{\text {tot }}=\text { the total breath duration } \\
\mathrm{dp} / \mathrm{dt}=\text { rate of rise of } \mathrm{P}_{\mathrm{di}}\end{array}$}} \\
\hline & & \\
\hline \multirow{2}{*}{\multicolumn{3}{|c|}{$\Delta \mathrm{PTP}=$ the difference between peak $\mathrm{P}_{\mathrm{mus}}-\mathrm{PTP}$ and $\mathrm{P}_{\mathrm{di}}-\mathrm{PTP}$}} \\
\hline \multicolumn{2}{|c|}{$\mathrm{f}=$ breathing frequency } & \\
\hline \multicolumn{3}{|l|}{ PEEPi = intrinsic PEEP } \\
\hline$\Delta \mathrm{P}_{\mathrm{gaa}} / \Delta \mathrm{P}_{\text {eos }}=$ change in gastric pressure to changes $\mathrm{i}$ & geal pressu & inspiration \\
\hline
\end{tabular}

shown in Supplementary Figure 1 (see the supplementary materials at http://www.rcjournal.com).

Bland-Altman analysis revealed limited agreement between peak $\mathrm{P}_{\text {mus }}$ and $\mathrm{P}_{\mathrm{di}}$, and between PTP-peak $\mathrm{P}_{\text {mus }}$ and

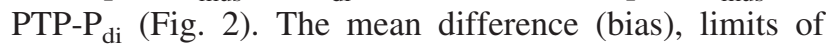
agreement, and corresponding $95 \%$ CIs of bias are shown in Table 2. Correlations between peak $\mathrm{P}_{\text {mus }}$, PTP-peak $\mathrm{P}_{\text {mus }}$, the difference between peak $\mathrm{P}_{\text {mus }}$ and $\mathrm{P}_{\mathrm{di}}$, and the difference between PTP peak $\mathrm{P}_{\text {mus }}$ and PTP $\mathrm{Pdi}_{\mathrm{Pdi}}$ with each of the possible confounding physiologic factors are shown in Supplementary Table 3 (see the supplementary materials at http://www.rcjournal.com). Significant positive correlations were found between the rate of increase in $\mathrm{dp} / \mathrm{dt}$ and both peak $\mathrm{P}_{\text {mus }}\left(r_{s}=0.49, P<.001\right)$ and PTP-peak $\mathrm{P}_{\text {mus }}$ $\left(r_{\mathrm{s}}=0.24, P=.03\right)$. The difference between peak $\mathrm{P}_{\text {mus }}$ and $\mathrm{P}_{\mathrm{di}}(\mathrm{dP})$ was inversely correlated with $\mathrm{dp} / \mathrm{dt}$ ([Spearman's rank correlation coefficient] $r_{s}=-0.39, P=.001$ ), which indicated an increase in $\mathrm{dP}$ with a decrease in $\mathrm{dp} / \mathrm{dt}$. A significant positive correlation was found between $\Delta \mathrm{PTP}$ and the difference between mechanical and neural inspiratory time $\left(r_{\mathrm{s}}=0.28, P=.04\right)$.

\section{Validation of the Proposed Algorithm}

Based on the proposed algorithm at peak $\mathrm{P}_{\text {mus }}$ of $<5$, 5-10, and $>10 \mathrm{~cm} \mathrm{H}_{2} \mathrm{O}$, inspiratory muscle effort was estimated to be $<50,50-150$, and $>150 \mathrm{~cm} \mathrm{H}_{2} \mathrm{O} \times \mathrm{s} / \mathrm{min}$, respectively; accordingly, the level of assistance was proposed as excessive (overassist), adequate, or insufficient (underassist).

Overall, in 31 of 63 experimental cases (49.21\%), the inspiratory effort determined by the PTP-P $\mathrm{P}_{\mathrm{di}}$ was classified in a different range than that predicted by the calculated peak $\mathrm{P}_{\text {mus }}$. The sensitivity and specificity of peak $\mathrm{P}_{\text {mus }}$ to predict the actual inspiratory effort and thus to correctly characterize the level of assist were $81.2 \%$ and $58.1 \%$, respectively. The area under the receiver operating characteristic curve was 0.70 (95\% CI $0.57-0.83 ; P=.012$ ) (Fig. 3).

\section{Subgroup 1: peak $\mathrm{P}_{\text {mus }}<5 \mathrm{~cm} \mathrm{H}_{2} \mathrm{O}$}

Peak $\mathrm{P}_{\text {mus }}$ was $<5 \mathrm{~cm} \mathrm{H}_{2} \mathrm{O}$ in 11 of 63 experimental cases, which suggests low inspiratory effort and an excessive level of assist. Inspiratory effort measured by PTP- $\mathrm{P}_{\mathrm{di}} / \mathrm{min}$ was within the range predicted by peak $\mathrm{P}_{\text {mus }}$ in 7 of 11 experimental cases $(63.64 \%)$. In the remaining experimental cases (4/11 [36.36\%]), PTP-P $\mathrm{P}_{\mathrm{di}} / \mathrm{min}$ was within acceptable limits (50-150 $\mathrm{cm} \mathrm{H}_{2} \mathrm{O} \times \mathrm{s} / \mathrm{min}$ ), which suggested an adequate level of assist.

\section{Subgroup 2: peak $P_{\text {mus }}$ of 5-10 $\mathrm{cm} \mathrm{H}_{2} \mathrm{O}$}

Peak $\mathrm{P}_{\text {mus }}$ ranged between 5 and $10 \mathrm{~cm} \mathrm{H}_{2} \mathrm{O}$ in 29 of 63 experimental cases, which indicated an adequate level of assist. Inspiratory effort measured by the PTP- $\mathrm{P}_{\mathrm{di}} / \mathrm{min}$ was within the range of inspiratory effort predicted by peak $\mathrm{P}_{\text {mus }}$ in 18 of 29 experimental cases (62.07\%). In 11 of 29 experimental cases $(37.93 \%)$, PTP- $\mathrm{P}_{\mathrm{di}} / \mathrm{min}$ was either $<50$ $(31.03 \%)$ or $>150 \mathrm{H}_{2} \mathrm{O} \times \mathrm{s} / \mathrm{min}(6.89 \%)$, which indicated excessive or insufficient ventilator assist, respectively.

\section{Subgroup 3: peak $\mathrm{P}_{\text {mus }}>10 \mathrm{~cm} \mathrm{H}_{2} \mathrm{O}$}

Peak $\mathrm{P}_{\text {mus }}$ was $>10 \mathrm{~cm} \mathrm{H}_{2} \mathrm{O}$ in 23 of 63 experimental cases, which indicated high inspiratory effort and insufficient ventilator assist. PTP- $\mathrm{P}_{\mathrm{di}} / \mathrm{min}$ was within the range predicted by peak $\mathrm{P}_{\text {mus }}$ in 4 of 23 experimental cases (17.39\%). PTP- $\mathrm{P}_{\mathrm{di}} /$ min ranged from 50 to $150 \mathrm{~cm} \mathrm{H}_{2} \mathrm{O} \times$ $\mathrm{s} / \mathrm{min}$ in 15 of 22 experimental cases $(65.21 \%)$, and was $<50 \mathrm{~cm} \mathrm{H}_{2} \mathrm{O} \times \mathrm{s} / \mathrm{min}$ in 4 of 22 experimental cases $(17.39 \%)$, which indicated adequate or excessive ventilator assist, respectively (Fig. 4). 

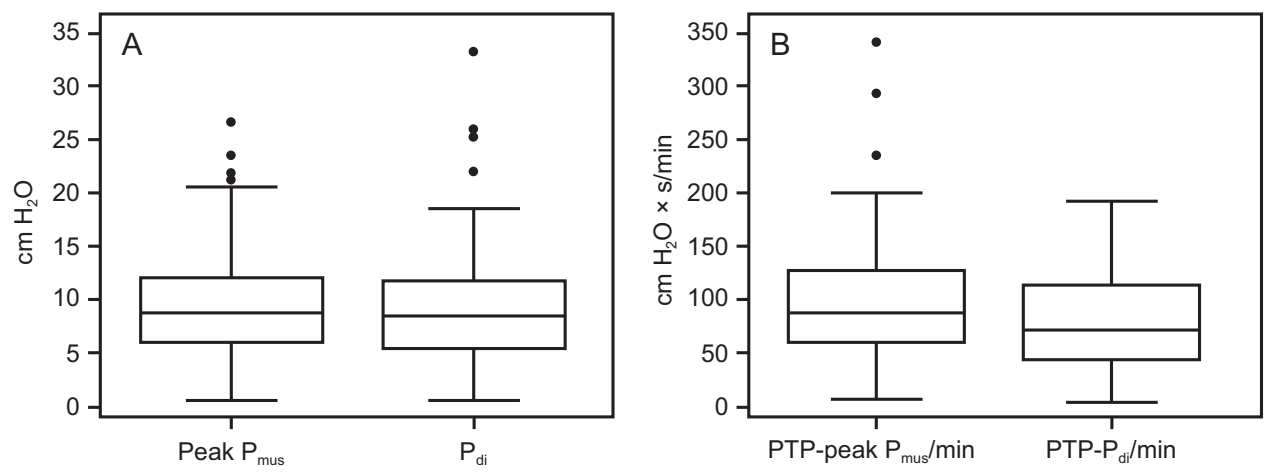

Fig. 1. Box and whiskers plots, representing a comparison of Peak $P_{\text {mus }}$ and $P_{d i}(A)$, and PTP-Peak $P_{\text {mus }}$ and PTP-P $P_{d i}(B)$.The lower and upper edges of each box represent the 25th and 75th percentiles, respectively. Median values are shown by the lines within each box. Whiskers represent adjacent values. Points denote outliers. Peak $P_{\text {mus }}=$ calculated peak inspiratory pressure; $P_{d i}=$ transdiaphragmatic pressure, $\mathrm{PTP}$-peak $\mathrm{P}_{\text {mus }}=$ calculated pressure-time product of peak $\mathrm{P}_{\text {mus }}$; $\mathrm{PTP}-\mathrm{P}_{\mathrm{di}}=$ pressure-time product of $\mathrm{P}_{\mathrm{di}}$.
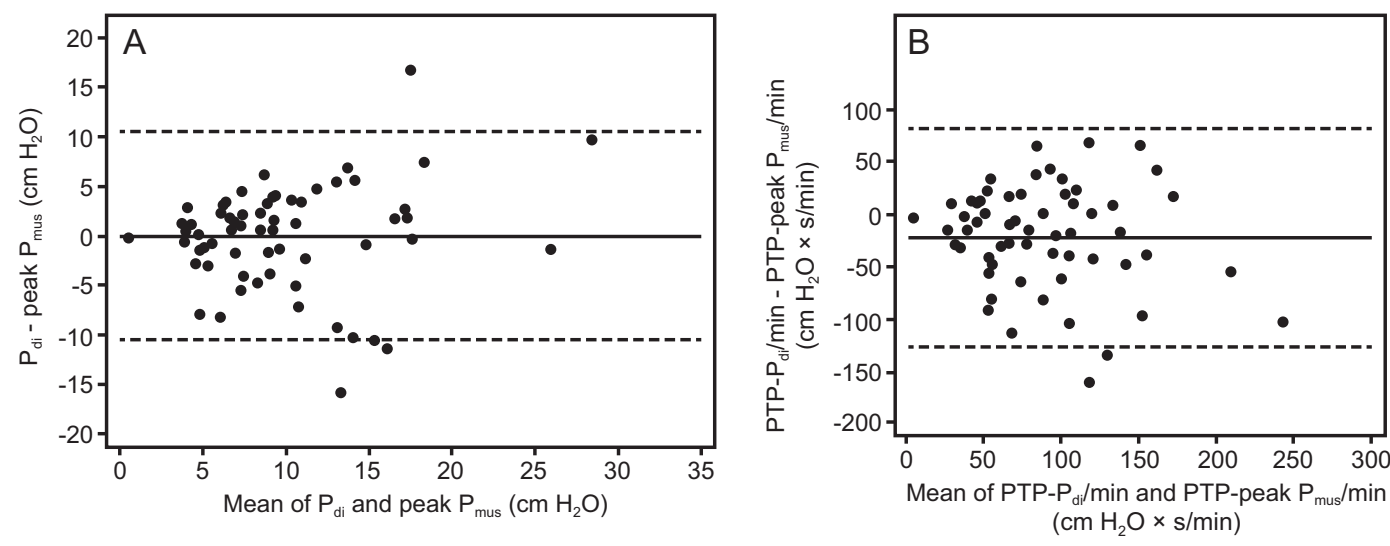

Fig. 2. Bland-Altman analysis presenting the mean difference (solid middle line) and $95 \% \mathrm{Cl}$ of the differences ( $\pm 1.96 \mathrm{SD}$ of the mean; dotted lines) between $\mathrm{P}_{\mathrm{di}}$ and peak $\mathrm{P}_{\text {mus }}(\mathrm{A})$ and between PTP- $\mathrm{P}_{\mathrm{di}}$ and PTP peak $\mathrm{P}_{\text {mus }}(\mathrm{B})$. Peak $\mathrm{P}_{\text {mus }}=$ calculated peak inspiratory pressure; $\mathrm{P}_{\mathrm{di}}=$ transdiaphragmatic pressure; $\mathrm{PTPP} \mathrm{di}_{\mathrm{i}} / \mathrm{min}=$ pressure-time product of $\mathrm{P}_{\mathrm{di}}$ per minute; $\mathrm{PTP}$-peak $\mathrm{P}_{\text {mus }} /$ min $=$ calculated pressure time product of peak $\mathrm{P}_{\text {mus }}$ per minute.

Table 2. Mean Difference (bias) of peak $\mathrm{P}_{\text {mus }}-\mathrm{P}_{\mathrm{di}}$ and PTP-peak $\mathrm{P}_{\text {mus }}-\mathrm{PTP}-\mathrm{P}_{\mathrm{di}}$, Limits of Agreement ( \pm 1.96 SD of the mean), and $95 \%$ CIs for the Mean and for the Upper and Lower Limits of Agreement

\begin{tabular}{|c|c|c|c|c|c|}
\hline Factor & $\begin{array}{c}\text { Mean } \\
\text { Difference }\end{array}$ & $\begin{array}{l}\text { Limits of } \\
\text { Agreements }\end{array}$ & $95 \%$ CI for the Bias & $\begin{array}{l}\text { 95\% CI for the } \\
\text { Upper Limit }\end{array}$ & $\begin{array}{l}95 \% \text { CI for the } \\
\text { Lower Limit }\end{array}$ \\
\hline peak $\mathrm{P}_{\text {mus }}-\mathrm{P}_{\mathrm{di}}, \mathrm{cm} \mathrm{H}_{2} \mathrm{O}$ & -0.059 & -10.54 to 10.42 & -1.40 to 1.28 & $8.10-12.73$ & -12.85 to -8.22 \\
\hline PTP peak $\mathrm{P}_{\text {mus }}-\mathrm{PTP}_{\text {Pdi }}, \mathrm{cm} \mathrm{H}_{2} \mathrm{O} \times \mathrm{s} / \mathrm{min}$ & 21.72 & -81.80 to 125.25 & $8.42-35.03$ & $102.39-148.10$ & -104.65 to -58.94 \\
\hline \multicolumn{6}{|c|}{$\begin{array}{l}\text { peak } \mathrm{P}_{\text {mus }}=\text { calculated (from the proposed formula) peak inspiratory pressure } \\
\mathrm{P}_{\mathrm{di}}=\text { transdiaphragmatic pressure } \\
\text { PTP = pressure-time product }\end{array}$} \\
\hline
\end{tabular}

\section{Discussion}

The most significant findings of the present study were the following: (1) there was limited agreement between formula-derived estimates of peak $\mathrm{P}_{\text {mus }}$ and effort PTPpeak $\mathrm{P}_{\text {mus }}$, and actual inspiratory pressure and effort measured by $\mathrm{P}_{\mathrm{di}}$ and PTP-P $\mathrm{P}_{\mathrm{di}}$, respectively, and (2) setting the ventilator assistance by using the proposed algorithm could result in either under- or overassistance in approximately half of the study cases.

With conventional modes of assisted ventilation, the assistance level is primarily determined based on the patient's breathing pattern; this frequently results in considerable dissociation between patient demands and ventila- 


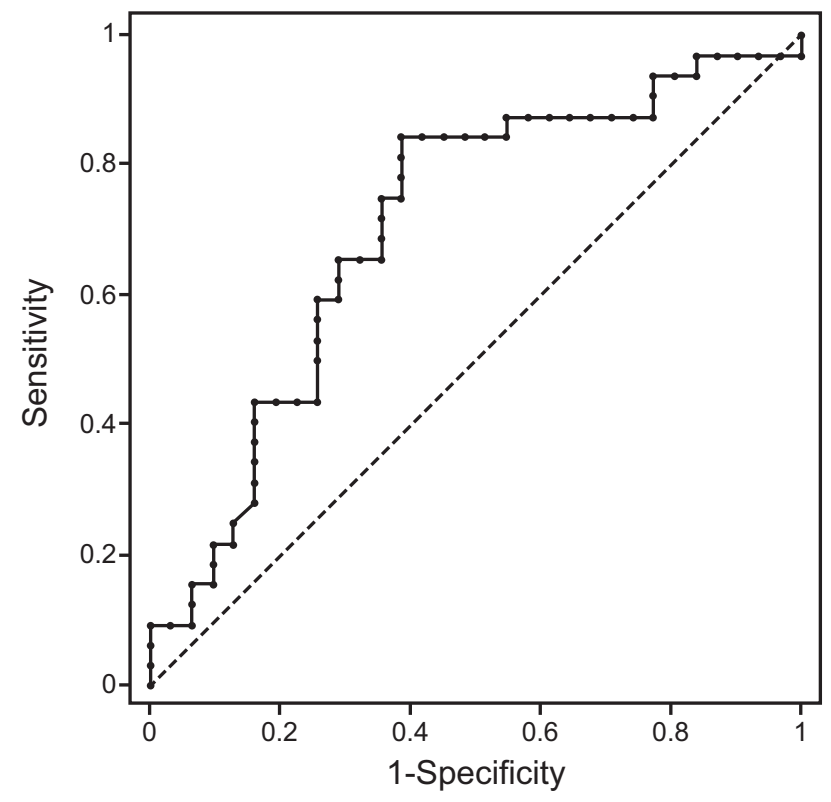

Fig. 3. Receiver operating curve for the prediction of the actual range of inspiratory effort by the calculated peak inspiratory pressure (peak $\mathrm{P}_{\text {mus }}$ ), showing an optimal criterion of $<9.85 \mathrm{~cm} \mathrm{H}_{2} \mathrm{O}$.

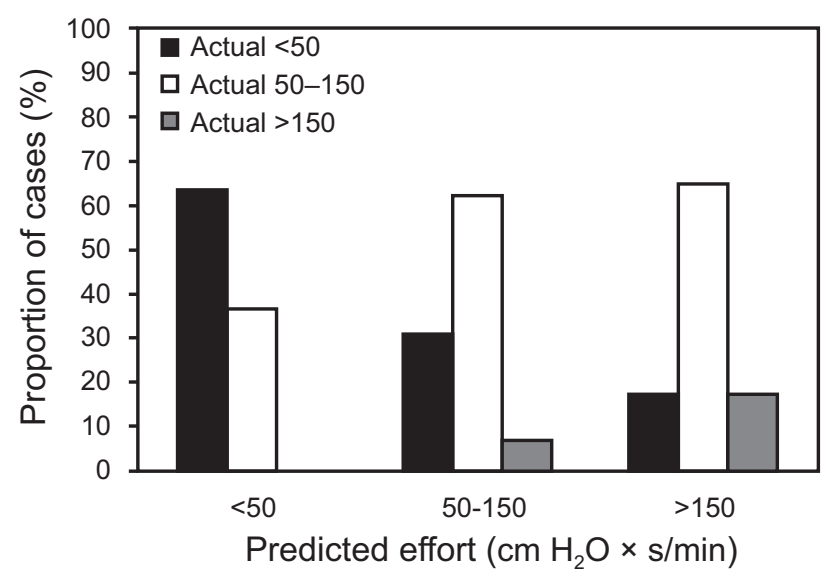

Fig. 4. Percentage of experimental cases with actual inspiratory effort (PTP- $\left.\mathrm{P}_{\mathrm{di}}\right)$ of $<50,50-150$, or $>150 \mathrm{~cm} \mathrm{H}_{2} \mathrm{O} \times \mathrm{s} / \mathrm{min}$, at each different range of predicted by peak $\mathrm{P}_{\text {mus }}$ inspiratory effort: $<50$, 50-150, and $>150 \mathrm{~cm} \mathrm{H}_{2} \mathrm{O} \times \mathrm{s} / \mathrm{min}$. Peak $\mathrm{P}_{\text {mus }}=$ calculated peak inspiratory pressure, PTP- $\mathrm{P}_{\mathrm{di}}$ : pressure-time product of transdiaphragmatic pressure per minute.

tor output. ${ }^{15-19}$ Conversely, $\mathrm{V}_{\mathrm{T}}$ and breathing frequency may be considerably modified by ventilator settings. ${ }^{20}$ During ventilation on $\mathrm{PAV}+$, titrating the assistance level by $\mathrm{V}_{\mathrm{T}}$ and breathing frequency may be of limited effectiveness. Significant variability in $\mathrm{V}_{\mathrm{T}}$ has been observed, and patients retain their desired breathing largely independent of mechanical load and assistance level., ${ }^{1,4,12}$

To simplify and unify titration of assistance level during ventilation on $\mathrm{PAV}+$, Carteaux et al ${ }^{10}$ introduced a simple algorithm, as described earlier in this article. However, that study did not validate the estimated variables or the proposed algorithm for assistance titration. In the present study, we validated the proposed algorithm by evaluating the accuracy of peak $\mathrm{P}_{\text {mus }}$ to predict the actual inspiratory effort, as determined by the accepted standard method of PTP-P ${ }_{d i}$. In up to $49 \%$ of cases, PTP-P ${ }_{d i}$ was in a different range from that predicted by peak $\mathrm{P}_{\text {mus }}$. Consequently, in nearly half of the experimental cases, gain adjustment by using the proposed algorithm could result in either overor under-ventilation assistance. The lowest accuracy of peak $\mathrm{P}_{\text {mus }}$ was present in the subgroup of experimental cases characterized by peak $\mathrm{P}_{\text {mus }}$ of $>10 \mathrm{~cm} \mathrm{H}_{2} \mathrm{O}$; in that subgroup, peak $\mathrm{P}_{\text {mus }}$ failed to predict the actual inspiratory effort in up to $83 \%$ of experimental cases.

Numerous studies have shown the deleterious effects of inappropriate assistance level (either excessive or insufficient) on the respiratory muscles. An excessive level of assistance results in diaphragmatic atrophy and contractile dysfunction. ${ }^{21-25}$ Mechanical ventilation-induced diaphragm atrophy is associated with diaphragmatic dysfunction, which has been related to unfavorable clinical outcomes. ${ }^{26-28}$ Excessive assistance may induce respiratory alkalosis, which, in patients with a preexisting low respiratory drive (ie, metabolic alkalosis and/or sedation) may promote periodic apnea. ${ }^{29,30}$ Furthermore, in patients with obstructive lung diseases ventilated in assisted modes, excessive assistance may lead to high $\mathrm{V}_{\mathrm{T}}$ and dynamic hyperinflation, which leads to triggering delay and ineffective efforts, thus adversely affecting patient outcomes. ${ }^{15,16}$ Conversely, when ventilator support is insufficient for patient demands, vigorous inspiratory efforts may result in self-inflicted lung injury. ${ }^{31-34}$ Furthermore, mismatch between ventilation demands and ventilator assistance may be associated with patient discomfort, increased work of breathing, and prolonged mechanical ventilation and ICU stay. The current study showed that the limited prediction value of peak $\mathrm{P}_{\text {mus }}$ was attributed to the disagreement between the estimated and actual inspiratory muscle output and effort.

\section{Comparison Between peak $\mathbf{P}_{\text {mus }}$ and $\mathbf{P}_{\mathrm{di}}$}

Although the difference was not statistically significant, we found low agreement between the 2 variables, indicated by the broad limit of agreement in the Bland-Altman analysis, significant scatter of the measurements, and low coefficient of correlation in the regression analysis. The discrepancy between these variables could arise from either a misleading calculation of peak $\mathrm{P}_{\text {mus }}$ and/or different physiologic factors related to both ventilator and subject characteristics.

The proposed equation for peak $\mathrm{P}_{\text {mus }}$ does not include PEEPi; therefore, peak $\mathrm{P}_{\text {mus }}$ is expected to be underestimated in patients who exhibit PEEPi. The extent of pres- 
sure underestimation depends on the levels of assistance and PEEPi; at low assistance and high levels of PEEPi, underestimation increases. In addition, because pressure delivery in PAV is driven by patient effort, the presence of PEEPi reduces the fraction of the patient's effort that is being assisted, which leads to underestimation of the proportion of assistance being provided. However, the presence of PEEPi may contribute minimally to disagreement between these compared variables; although we included a relatively high proportion of subjects with COPD, we found a low level of PEEPi (median value of $1.5 \mathrm{~cm} \mathrm{H}_{2} \mathrm{O}$ ). At this level of PEEPi, underestimation is minimal, even at low levels of assist. Both ventilator and patient characteristics, including triggering delay, inspiratory muscle output, dynamic hyperinflation, expiratory and accessory muscle activity, and patient respiratory drive may also contribute (either separately or collectively) to the dissociation between peak $\mathrm{P}_{\text {mus }}$ and $\mathrm{P}_{\mathrm{di}}$.

Collectively, for all experimental cases, respiratory drive was the sole factor that significantly correlated with the difference between the estimated and the actual peak muscle pressure; as respiratory drive increased, the difference in peak muscle pressure decreased. This association is likely attributed to associated changes in peak $\mathrm{P}_{\text {mus }}$ because we found a significant positive correlation between peak $\mathrm{P}_{\text {mus }}$ and the respiratory drive. Changes in respiratory drive may alter ventilator output, mainly through changes in triggering delay. ${ }^{18,35,36}$ Because the $\mathrm{P}_{\mathrm{aw}}$ value is the primary determinant in the peak $\mathrm{P}_{\text {mus }}$ calculation, any increase or decrease of $\mathrm{P}_{\mathrm{aw}}$ results in changes in the calculated peak pressure. Nevertheless, our data indicated that, for individual experimental cases, the difference between peak $\mathrm{P}_{\text {mus }}$ and $\mathrm{P}_{\mathrm{di}}$ should be attributed to multiple factors rather than strictly to changes in respiratory drive. For example, we found that peak $\mathrm{P}_{\text {mus }}$ was significantly higher than $\mathrm{P}_{\mathrm{di}}$ in experimental cases with relatively low respiratory muscle output and respiratory drive, and relatively high triggering delay. The inverse relationship was also observed.

\section{Comparison Between PTP-peak $\mathbf{P}_{\text {mus }}$ and PTP-P $\mathbf{d i}_{\mathrm{d}}$}

We found a significant difference between the inspiratory effort estimated by the proposed formula and actual inspiratory effort measured by $\mathrm{P}_{\mathrm{di}}\left(\mathrm{PTP}-\mathrm{P}_{\mathrm{di}}\right)$. This finding was demonstrated by both the low agreement between compared variables in Bland-Altman analysis as well as regression analysis. Disagreement between PTP-peak $\mathrm{P}_{\text {mus }}$ and PTP- $\mathrm{P}_{\mathrm{di}}$ can mainly be attributed to the assumptions on which the calculations were based. First, PTP-peak $P_{\text {mus }}$ was calculated as the area under the corresponding waveform during the inspiratory time when assuming that the rate of increase of inspiratory muscle pressure is constant (linear during neural inspiration); this resulted in a triangular area under the waveform. Nevertheless, results of physiologic studies indicate that the rate of increase in inspiratory muscle pressure $\left(\mathrm{P}_{\text {mus }}\right)$ or $\mathrm{P}_{\mathrm{di}}$ typically exhibits a concave or convex shape. ${ }^{37}$ Consequently, the area under the $\mathrm{P}_{\mathrm{di}}$ waveform or pressure generated by respiratory muscles, or is expected to either be lower (in a concave shape) or higher (in a convex shape) compared with the area in the linear waveform (Supplementary Fig. 2 [see the supplementary materials at http://www.rcjournal.com]).

Second, PTP-peak $\mathrm{P}_{\text {mus }}$ was calculated based on the assumption that mechanical and neural inspiratory times were equal. Ideally, during assisted modes, the neural time may coincide with mechanical time. However, mechanical inspiration typically ends either before or after the end of neural inspiration, ${ }^{17,18,35,38}$ even in modes in which inspiratory effort drives ventilation, as in $\mathrm{PAV} / \mathrm{PAV}+.4,12$ Because PTP-peak $\mathrm{P}_{\text {mus }}$ is calculated by using the mechanical inspiratory time for a specific peak $\mathrm{P}_{\text {mus }}$ value, the derived PTP is expected to vary with the mechanical time (relative to neural time). In nearly all experimental cases in the present study, the mechanical time was higher than neural time, largely due to triggering delay.

The contribution of the difference between the neural and mechanical inspiratory time to the difference between PTP-peak $\mathrm{P}_{\text {mus }}$ and PTP- $\mathrm{P}_{\mathrm{di}}$ was supported by a significant positive correlation between $\triangle \mathrm{PTP}$ and the difference between neural and mechanical inspiratory times; increased time difference was associated with an increased difference between PTP-peak $\mathrm{P}_{\text {mus }}$ and PTP- $\mathrm{P}_{\mathrm{di}}$. Evidently, in individual experimental cases, the difference between PTPpeak $\mathrm{P}_{\text {mus }}$ and PTP- $\mathrm{P}_{\mathrm{di}}$ can be attributed to by a combination of the above, at variable degrees of participation. Our findings were in agreement with those of a study by Su et al. ${ }^{11}$ peak $\mathrm{P}_{\text {mus }}$ and the derived PTP were compared with Pmus, as calculated from $\mathrm{P}_{\mathrm{es}}$. Although the design and study population varied between the 2 studies, both revealed a weak correlation between estimated and actual inspiratory muscle output and effort.

\section{Limitations and Clinical Implications}

This study was a retrospective validation of proposed formulas to estimate peak muscle pressure and effort during ventilation with PAV + and not clinically evaluate the proposed algorithm. The number of patients included here was lower than that in the study that proposed the algorithm. Analysis of our data showed high variability in the causes of error in the estimated values, which suggested that other sources of error may be identified by using a larger patient sample. The aim of setting the level of assist based on patient effort to avoid over- or underassist remains undisputed. However, this study highlighted the complexities of accurately estimating patient effort without invasive measurements and emphasized the need for 
further research in this direction. When adjusting the level of assist in PAV+, the caregiver may use the proposed algorithm as a starting point and may then adjust the assist level according to patient comfort and gas exchange.

\section{Conclusions}

This study showed that, in subjects on mechanical ventilation and with the PAV + mode, there was significant disagreement between the actual and estimated respiratory muscle pressure and effort due to factors related to both subject and ventilator characteristics. Estimated peak inspiratory pressure showed limited accuracy in predicting actual inspiratory muscle effort; therefore, in nearly half of the analyzed experimental cases, adjusting the assistance level with the proposed algorithm could have led to overor under-ventilator assist.

\section{REFERENCES}

1. Younes M. Proportional assist ventilation, a new approach to ventilatory support. Theory. Am Rev Respir Dis 1992;145(1):114-120.

2. Younes M, Kun J, Masiowski B, Webster K, Roberts D. A method for noninvasive determination of inspiratory resistance during proportional assist ventilation. Am J Respir Crit Care Med 2001;163(4): 829-839.

3. Younes M, Webster K, Kun J, Roberts D, Masiowski B. A method for measuring passive elastance during proportional assist ventilation. Am J Respir Crit Care Med 2001;164(1):50-60.

4. Kondili E, Prinianakis G, Alexopoulou C, Vakouti E, Klimathianaki M, Georgopoulos D. Respiratory load compensation during mechanical ventilation-proportional assist ventilation with load-adjustable gain factors versus pressure support. Intensive Care Med 2006;32(5): 692-699.

5. Xirouchaki N, Kondili E, Klimathianaki M, Georgopoulos D. Is proportional-assist ventilation with load-adjustable gain factors a user-friendly mode? Intensive Care Med 2009;35(9):1599-1603.

6. Xirouchaki N, Kondili E, Vaporidi K, Xirouchakis G, Klimathianaki M, Gavriilidis G, et al. Proportional assist ventilation with loadadjustable gain factors in critically ill patients: comparison with pressure support. Intensive Care Med 2008;34(11):2026-2034.

7. Alexopoulou C, Kondili E, Plataki M, Georgopoulos D. Patientventilator synchrony and sleep quality with proportional assist and pressure support ventilation. Intensive Care Med 2013;39(6):10401047.

8. Alexopoulou C, Kondili E, Vakouti E, Klimathianaki M, Prinianakis G, Georgopoulos D. Sleep during proportional-assist ventilation with load-adjustable gain factors in critically ill patients. Intensive Care Med 2007;33(7):1139-1147.

9. Younes M, Puddy A, Roberts D, Light RB, Quesada A, Taylor K, et al. Proportional assist ventilation. Results of an initial clinical trial. Am Rev Respir Dis 1992;145(1):121-129.

10. Carteaux G, Mancebo J, Mercat A, Dellamonica J, Richard JC, Aguirre-Bermeo H, et al. Bedside adjustment of proportional assist ventilation to target a predefined range of respiratory effort. Crit Care Med 2013;41(9):2125-2132.

11. Su PL, Kao PS, Lin WC, Su PF, Chen CW. Limited predictability of maximal muscular pressure using the difference between peak airway pressure and positive end-expiratory pressure during proportional assist ventilation (PAV). Crit Care 2016;20(1):382.
12. Akoumianaki E, Prinianakis G, Kondili E, Malliotakis P, Georgopoulos D. Physiologic comparison of neurally adjusted ventilator assist, proportional assist and pressure support ventilation in critically ill patients. Respir Physiol Neurobiol 2014;203:82-89.

13. Akoumianaki E, Maggiore SM, Valenza F, Bellani G, Jubran A, Loring SH, et al.; PLUG Working Group (Acute Respiratory Failure Section of the European Society of Intensive Care Medicine. The application of esophageal pressure measurement in patients with respiratory failure. Am J Respir Crit Care Med 2014;189(5):520531.

14. Parthasarathy S, Jubran A, Tobin MJ. Cycling of inspiratory and expiratory muscle groups with the ventilator in airflow limitation. Am J Respir Crit Care Med 1998;158(5 Pt 1):1471-1478.

15. Thille AW, Rodriguez P, Cabello B, Lellouche F, Brochard L. Patient-ventilator asynchrony during assisted mechanical ventilation. Intensive Care Med 2006;32(10):1515-1522.

16. Vaporidi K, Babalis D, Chytas A, Lilitsis E, Kondili E, Amargianitakis $\mathrm{V}$, et al. Clusters of ineffective efforts during mechanical ventilation: impact on outcome. Intensive Care Med 2017;43(2):184191.

17. Du HL, Yamada Y. Expiratory asynchrony. Respir Care Clin N Am 2005;11(2):265-280.

18. Kondili E, Prinianakis G, Georgopoulos D. Patient-ventilator interaction. Br J Anaesth 2003;91(1):106-119.

19. Kondili E, Xirouchaki N, Georgopoulos D. Modulation and treatment of patient-ventilator dyssynchrony. Curr Opin Crit Care 2007; 13(1):84-89.

20. Younes M. Patient-ventilator interaction with pressure-assisted modalities of ventilatory support. Semin Respir Med 1993;14:299-322.

21. Shanely RA, Zergeroglu MA, Lennon SL, Sugiura T, Yimlamai T, Enns D, et al. Mechanical ventilation-induced diaphragmatic atrophy is associated with oxidative injury and increased proteolytic activity. Am J Respir Crit Care Med 2002;166(10):1369-1374.

22. Jaber S, Petrof BJ, Jung B, Chanques G, Berthet JP, Rabuel C, et al. Rapidly progressive diaphragmatic weakness and injury during mechanical ventilation in humans. Am J Respir Crit Care Med 2011; 183(3):364-371.

23. Hudson MB, Smuder AJ, Nelson WB, Bruells CS, Levine S, Powers SK. Both high level pressure support ventilation and controlled mechanical ventilation induce diaphragm dysfunction and atrophy. Crit Care Med 2012;40(4):1254-1260.

24. Powers SK, Shanely RA, Coombes JS, Koesterer TJ, McKenzie M, Van Gammeren D, et al. Mechanical ventilation results in progressive contractile dysfunction in the diaphragm. J Appl Physiol (1985) 2002;92(5):1851-1858.

25. Goligher EC, Fan E, Herridge MS, Murray A, Vorona S, Brace D, et al. Evolution of diaphragm thickness during mechanical ventilation. impact of inspiratory effort. Am J Respir Crit Care Med 2015;192(9): 1080-1088.

26. Goligher EC, Dres M, Fan E, Rubenfeld GD, Scales DC, Herridge MS, et al. Mechanical ventilation-induced diaphragm atrophy strongly impacts clinical outcomes. Am J Respir Crit Care Med 2018;197(2): 204-213.

27. Demoule A, Jung B, Prodanovic H, Molinari N, Chanques G, Coirault $\mathrm{C}$, et al. Diaphragm dysfunction on admission to the intensive care unit. Prevalence, risk factors, and prognostic impact-a prospective study. Am J Respir Crit Care Med 2013;188(2):213-219.

28. Demoule A, Molinari N, Jung B, Prodanovic H, Chanques G, Matecki S, et al. Patterns of diaphragm function in critically ill patients receiving prolonged mechanical ventilation: a prospective longitudinal study. Ann Intensive Care 2016;6(1):75.

29. Meza S, Mendez M, Ostrowski M, Younes M. Susceptibility to periodic breathing with assisted ventilation during sleep in normal subjects. J Appl Physiol (1985) 1998;85(5):1929-1940. 


\section{Algorithm FOR Titrating PAV+}

30. Parthasarathy S, Tobin MJ. Effect of ventilator mode on sleep quality in critically ill patients. Am J Respir Crit Care Med 2002;166(11):1423-1429.

31. Yoshida T, Fujino Y, Amato MB, Kavanagh BP. Fifty years of research in ARDS. Spontaneous breathing during mechanical ventilation. risks, mechanisms, and management. Am J Respir Crit Care Med 2017;195(8):985-992.

32. Yoshida T, Torsani V, Gomes S, De Santis RR, Beraldo MA, Costa EL, et al. Spontaneous effort causes occult pendelluft during mechanical ventilation. Am J Respir Crit Care Med 2013;188(12):1420-1427.

33. Yoshida T, Uchiyama A, Matsuura N, Mashimo T, Fujino Y. Spontaneous breathing during lung-protective ventilation in an experimental acute lung injury model: high transpulmonary pressure associated with strong spontaneous breathing effort may worsen lung injury. Crit Care Med 2012;40(5):1578-1585.

34. Vassilakopoulos T, Divangahi M, Rallis G, Kishta O, Petrof B, Comtois A, et al. Differential cytokine gene expression in the dia- phragm in response to strenuous resistive breathing. Am J Respir Crit Care Med 2004;170(2):154-161.

35. Georgopoulos D, Prinianakis G, Kondili E. Bedside waveforms interpretation as a tool to identify patient-ventilator asynchronies. Intensive Care Med 2006;32(1):34-47.

36. Fabry B, Guttmann J, Eberhard L, Bauer T, Haberthür C, Wolff G. An analysis of desynchronization between the spontaneously breathing patient and ventilator during inspiratory pressure support. Chest 1995;107(5):1387-1394.

37. Georgopoulos D. Effect of mechanical ventilation on control of breathing. In: Tobin M, editor. Principals and practice of mechanical ventilation. New York: McGraw Hill; 2013:813-820.

38. Yamada Y, Du HL. Analysis of the mechanisms of expiratory asynchrony in pressure support ventilation: a mathematical approach. J Appl Physiol (1985) 2000;88(6):2143-2150.

This article is approved for Continuing Respiratory Care Education credit. For information and to obtain your CRCE

(free to AARC members) visit

www.rcjournal.com 